\title{
Comparative study of aqueous and oily pilocarpine in the production of ocular hypotension
}

\author{
S. C. BHOJWANI AND D. KNIGHT JONES \\ From the Department of Ophthalmology, Queen's Medical Centre, \\ University Hospital, Nottingham NG7 $2 U H$
}

SUMMARY The effective use of aqueous and oily pilocarpine was studied in 19 glaucomatous eyes. The aqueous drops were used 4 times a day while the oily drops were used only twice. It was found that the oily drops were better than the aqueous drops in lowering the mean intraocular pressure and the maximum pressure reached during the day. No statistically significant difference was found between the 2 pilocarpine treatments in the reduction of daily variation of intraocular pressure. It is felt that oily drops used only twice a day would lead to better patient compliance and better control of chronic simple glaucoma.

Pilocarpine is the most commonly used drug in the management of open-angle glaucoma. It is used as a nitrate or a hydrochloride with methylcellulose ${ }^{1}$ or $1.4 \%$ polyvinyl alcohol. ${ }^{2}{ }^{3}$ It has a short duration of action of 4-6 hours. This necessitates its being administered 4 times a day, causing discomfort because of its side effects each time it is instilled. Spasm of the ciliary muscle reduces accommodation and affects the refractive state, and rapid miosis causes dimming of vision.

A continuous-release preparation of pilocarpine will not only require infrequent instillations, so important to elderly patients, but will also reduce the symptoms associated with each instillation. Its efficacy in gel $^{4}$ once a day was found to be effective and more convenient than drops 4 times a day. We compared the use of pilocarpine in castor oil twice a day with its aqueous form 4 times a day in 19 eyes with chronic simple glaucoma.

\section{Materials and methods}

Nineteen eyes of 11 patients ranging in age from 57 to 81 years were studied. Each patient had been receiving treatment for chronic simple glaucoma for over 2 years. All the patients studied were chosen from the Eye Outpatient Department, University Hospital, Nottingham.

Correspondence to Dr S. C. Bhojwani, Department of Ophthalmology, Queen's Medical Centre, University Hospital, Nottingham NG7 2UH.
The patients were admitted to hospital, and the aqueous pilocarpine drops were discontinued for 24 hours. All other antiglaucomatous medications, if prescribed, were unaltered throughout the trial. On the second day of admission a controlled phasing was done 4 times a day with a Goldmann applanation tonometer. On the third day of admission the tensions were taken in a similar manner, with 9 eyes receiving aqueous pilocarpine drops 4 times a day and 10 eyes receiving oily pilocarpine drops twice a day. The percentage concentration of aqueous and oily pilocarpine was the same as the patient had been taking before the trial. Topical application of pilocarpine was withheld on the third day and the intraocular pressures were not recorded. On the final day the tensions were recorded with 9 patients receiving oily pilocarpine drops and 10 patients receiving the aqueous form.

The intraocular tensions were measured on the same tonometer by the same examiner, and the mean of 3 readings was taken. The examiner was unaware of the type of pilocarpine instilled, and the patients were asked to note any difference in the 'first' and 'second' medications.

\section{Results}

The mean daily pressure in 19 eyes (Table 1) was $21 \mathrm{mmHg}$ when oily drops were used as against $23.7 \mathrm{mmHg}$ when the aqueous drops were used. The mean intraocular pressure without the use of pilocarpine was $27.3 \mathrm{mmHg}$. The maximum, minimum, 
Table 1 Mean daily pressures

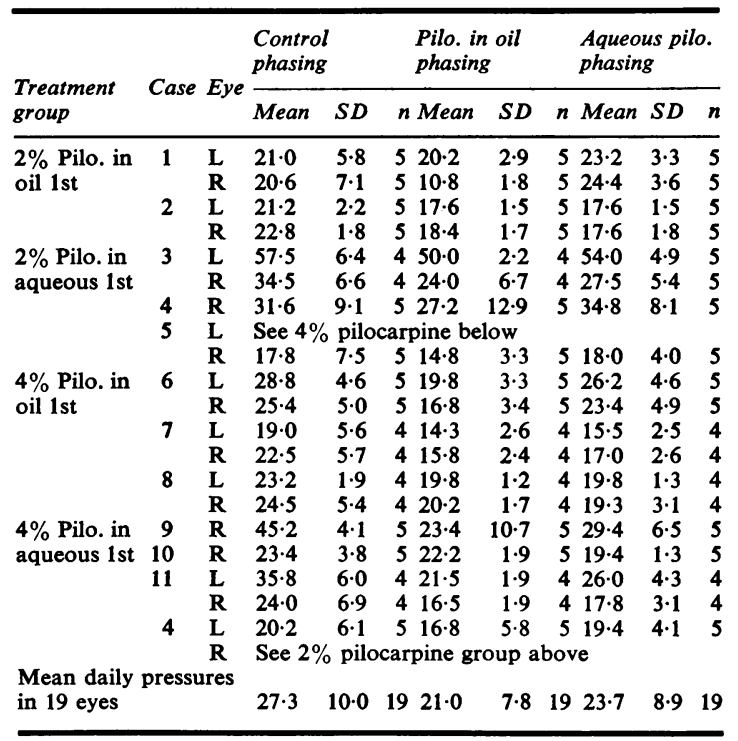

and maximum daily variation of intraocular pressure during phasing is shown in Table 2.

The average maximum intraocular pressure reached without treatment with pilocarpine (Table 3) was $34.1 \mathrm{mmHg}$, which was higher than when pilocarpine was being instilled. The maximum pressure was $26.6 \mathrm{mmHg}$ when the oily drops were used and $28.4 \mathrm{mmHg}$ when the aqueous drops were used.

The average maximum variation of intraocular pressure was found to be $8.6 \mathrm{mmHg}$ with oily
Table 3 Average maximum intraocular pressure and average maximum variation

\begin{tabular}{llllllllllll}
\hline & $\begin{array}{l}\text { Control } \\
\text { phasing }\end{array}$ & & \multicolumn{3}{l}{$\begin{array}{l}\text { Pilo. in oil } \\
\text { phasing }\end{array}$} & \multicolumn{4}{l}{$\begin{array}{l}\text { Aqueous pilo. } \\
\text { phasing }\end{array}$} \\
\cline { 2 - 10 } & Mean & $S D$ & $n$ & Mean & $S D$ & $n$ & Mean & $S D$ & $n$ \\
\hline $\begin{array}{l}\text { Maximum } \\
\text { pressure }\end{array}$ & 34.1 & 9.9 & 19 & 26.6 & 10.0 & 19 & 28.4 & 10.6 & 19 \\
$\begin{array}{l}\text { Maximum } \\
\text { variation }\end{array}$ & 12.4 & 4.8 & 19 & 8.6 & 7.3 & 19 & 9.1 & 5.0 & 19 \\
\hline
\end{tabular}

drops, 9.5 $\mathrm{mmHg}$ with aqueous drops, and $12.4 \mathrm{mmHg}$ without any pilocarpine treatment.

Analysis by paired $t$ tests (Table 4) shows that pilocarpine in oil gave statistically significant lower mean intraocular pressures than aqueous pilocarpine, and both pilocarpine in oil and aqueous gave statistically significantly lower mean intraocular pressures than were found in the control period (no treatment).

An analysis of the maximum intraocular pressures during phasing shows that the maximum intraocular pressure observed with aqueous pilocarpine was statistically significantly higher than that observed with pilocarpine in oil (Table 5). Table 6

Table 4 Treatment comparison regarding mean intraocular pressure

\begin{tabular}{lllll}
\hline Treatment comparison & $\begin{array}{l}\text { Mean } \\
\text { diff. }\end{array}$ & DF & t value & $\begin{array}{l}\text { p Value } \\
\text { (2-tailed) }\end{array}$ \\
\hline Pilo. in oil vs. control & 6.31 & 18 & 5.37 & 0.001 \\
Aqueous pilo. vs. control & 3.62 & 18 & 3.45 & 0.005 \\
Pilo. in oil vs. aqueous pilo. & 2.69 & 18 & 4.07 & 0.001 \\
\hline
\end{tabular}

$\mathrm{DF}=$ degrees of freedom.

Table 2 Maximum, minimum, and maximum daily variation of intraocular pressure

\begin{tabular}{|c|c|c|c|c|c|c|c|c|c|c|c|}
\hline \multirow{2}{*}{ Treatment group } & \multirow{2}{*}{ Case } & \multirow{2}{*}{ Eye } & \multicolumn{3}{|c|}{ Control phasing } & \multicolumn{3}{|c|}{ Pilo. in oil phasing } & \multicolumn{3}{|c|}{ Aqueous pilo. phasing } \\
\hline & & & Max. & Min. & Max. var. & Max. & Min. & Max. var. & $\operatorname{Max}$. & Min. & Max. var. \\
\hline \multirow[t]{4}{*}{$2 \%$ Pilo. in oil 1st } & 1 & $\mathbf{L}$ & 29 & 15 & 14 & 25 & 18 & 7 & 26 & 18 & 8 \\
\hline & & $\overline{\mathbf{R}}$ & 30 & 14 & 16 & 22 & 18 & 4 & 30 & 22 & 8 \\
\hline & 2 & L & 25 & 20 & 5 & 20 & 16 & 4 & 20 & 16 & 4 \\
\hline & & $\mathbf{R}$ & 24 & 20 & 4 & 20 & 16 & 4 & 20 & 15 & 5 \\
\hline \multirow{5}{*}{$2 \%$ Pilo. aqueous 1 st } & 3 & $\mathbf{L}$ & 62 & 48 & 14 & 53 & 48 & 5 & 60 & 48 & 12 \\
\hline & & $\mathbf{R}$ & 42 & 28 & 14 & 32 & 16 & 16 & 34 & 23 & 11 \\
\hline & 4 & $\mathbf{R}$ & 46 & 24 & 22 & 46 & 12 & 24 & 46 & 12 & 24 \\
\hline & 5 & $\mathbf{L}$ & \multicolumn{9}{|c|}{ See $2 \%$ pilocarpine group below } \\
\hline & & $\mathbf{R}$ & 30 & 12 & 18 & 20 & 12 & 8 & 24 & 14 & 10 \\
\hline \multirow{6}{*}{$4 \%$ Pilo. in oil 1 st } & 6 & $\mathbf{L}^{\prime}$ & 34 & 22 & 12 & 25 & 16 & 9 & 32 & 20 & 12 \\
\hline & & $\mathbf{R}$ & 32 & 18 & 14 & 22 & 13 & 9 & 28 & 17 & 11 \\
\hline & 7 & $\mathbf{L}$ & 26 & 14 & 12 & 18 & 12 & 6 & 18 & 12 & 6 \\
\hline & & $\mathbf{R}$ & 26 & 14 & 12 & 19 & 14 & 5 & 20 & 14 & 6 \\
\hline & 8 & $\mathbf{L}$ & 26 & 23 & 3 & 21 & 18 & 3 & 21 & 18 & 3 \\
\hline & & $\mathbf{R}$ & 32 & 20 & 12 & 22 & 18 & 4 & 22 & 15 & 7 \\
\hline \multirow[t]{6}{*}{$4 \%$ Pilo. aqueous 1st } & 9 & $\mathbf{R}$ & 48 & 38 & 10 & 41 & 12 & 29 & 38 & 23 & 15 \\
\hline & 10 & $\mathbf{R}$ & 28 & 20 & 8 & 25 & 21 & 4 & 20 & 18 & 2 \\
\hline & 11 & $\mathbf{L}$ & 44 & 30 & 14 & 24 & 20 & 4 & 32 & 22 & 10 \\
\hline & & $\mathbf{R}$ & 34 & 18 & 16 & 18 & 14 & 4 & 22 & 15 & 7 \\
\hline & 4 & $\mathbf{L}$ & 30 & 15 & 15 & 26 & 12 & 14 & 26 & 15 & 11 \\
\hline & & $\mathbf{R}$ & \multicolumn{9}{|c|}{ See $2 \%$ pilocarpine group above } \\
\hline
\end{tabular}


Table 5 Treatment comparison regarding daily maximum intraocular pressure

\begin{tabular}{lllll}
\hline Treatment comparison & $\begin{array}{l}\text { Mean } \\
\text { diff. }\end{array}$ & DF & t value & $\begin{array}{l}\text { p Value } \\
\text { (2-tailed) }\end{array}$ \\
\hline Pilo. in oil vs. control & $7 \cdot 84$ & 18 & $7 \cdot 42$ & 0.001 \\
Aqueous pilo. vs. control & $5 \cdot 74$ & 18 & 6.82 & 0.001 \\
Pilo. in oil vs. aqueous pilo. & $2 \cdot 10$ & 18 & 2.46 & 0.05 \\
\hline
\end{tabular}

Table 6 Treatment comparison regarding maximum daily variation of intraocular pressure

\begin{tabular}{|c|c|c|c|c|}
\hline Treatment comparison & $\begin{array}{l}\text { Mean } \\
\text { diff. }\end{array}$ & $D F$ & t Value & $\begin{array}{l}p \text { Value } \\
\text { (2-tailed) }\end{array}$ \\
\hline $\begin{array}{l}\text { Pilo. in oil vs. control } \\
\text { Aqueous pilo. vs. control } \\
\text { Pilo. in oil vs. aqueous pilo. }\end{array}$ & $\begin{array}{l}3 \cdot 79 \\
3 \cdot 32 \\
0 \cdot 47\end{array}$ & $\begin{array}{l}18 \\
18 \\
18\end{array}$ & $\begin{array}{l}2 \cdot 31 \\
3 \cdot 85 \\
0 \cdot 45\end{array}$ & $\begin{array}{l}0.05 \\
0.002 \\
\text { NS }\end{array}$ \\
\hline
\end{tabular}

shows that the maximum daily variation of intraocular pressure was statistically significantly greater in the control period. No statistical difference was found between aqueous and oil pilocarpine.

\section{Discussion}

Reduced patient compliance can be disastrous in the medical management of chronic simple glaucoma. A considerable number of patients in whom medical management has failed have been found to have been careless in putting in drops. Goldberg et al. ${ }^{4}$ showed that pilocarpine in gel once a day improved patient compliance.

Pilocarpine in oil used twice a day reduced the mean intraocular pressure more than aqueous pilocarpine 4 times a day. The maximum pressure during the day was significantly lower on oily pilocarpine drops twice a day than on aqueous drops 4 times a day. Although we were unable to get a statistically favourable difference in variation of the intraocular pressure on the 2 pilocarpine treatments, the need to use the oily drops only twice a day was an advantage.

We thank Dr Pearson, lecturer in community health, Medical School, Nottingham, for carrying out the statistical analysis, and Smith and Nephew Research Ltd for providing the pilocarpine in castor oil.

\section{References}

1 Borgmann H, Wurster W. Der Einffluss unterschiedlicher Konzentrationen und Vehikel auf die Pilocarpin-Miosis II. Unterschiedliche Vehikel. Klin Monatsbl Augenheilkd 1973; 163: 51-6.

2 Saari M, Koskela P, Masar SE. The effect of vehicle on pilocarpine-induced miosis. Acta Ophthalmol (Kbh) 1978; 56: 496-503.

3 Saari M, Koskela P, Masar SE. The effect of vehicle on pilocarpine-induced ocular hypotension. Acta Ophthalmol (Kbh) 1978; 56: 489-95.

4 Goldberg I, Ashburn FS, Kass MA, Becker B. Efficacy and patient acceptance of pilocarpine in gel. Am J Ophthalmol 1979; 88: 843-6. 